product was dried to coustant weight over calcium chloride and then analyzed as follows:--

It was dissolved in sulphuric acid and both the thallium and the chromium were reduced by sulphur dioxide; the chromium was precipitated by ammonia and filtered and weighed in the usual manner. The filtrate, containing the thallium, was acidified with sulphuric acid, and boiled six minutes to expel the excess of sulphur dioxide, or longer if necessary to evaporate to the required volume, then titrated with potassium permanganate after adding the usual amount of concentrated hydrochloric acid. Water of crystallization was determined by the loss of weight on heating to $200^{\circ}$. The potassium was weighed as the sulphate after reducing the thallium and chromium with sulphur dioxide and removing them by precipitation with ammonium sulphide.

\begin{tabular}{|c|c|c|}
\hline I & II & $\begin{array}{l}\text { Calculated for } \\
\left.\text { KTI(CrO })_{2}\right)_{2} 2 \mathrm{H}_{2} \mathrm{O}\end{array}$ \\
\hline 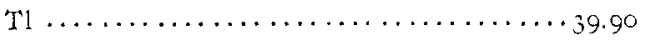 & 40.10 & 39.98 \\
\hline $\mathrm{Cr} \ldots \ldots \ldots \ldots \ldots \ldots \ldots \ldots \ldots \ldots \ldots \ldots+20.30$ & 20.13 & 20.35 \\
\hline$K \ldots \ldots \ldots \ldots \ldots \ldots \ldots \ldots \ldots \ldots \ldots \ldots \ldots, 7^{2} 2$ & 7.54 & 7.65 \\
\hline 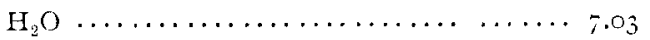 & 7.00 & 7.04 \\
\hline
\end{tabular}

This double chromate of potassium and trivalent thallium is a yellow crystalline precipitate, difficultly soluble in a solution of potassium dichromate, but quite readily soluble in dilute mineral acids. It is quickly hydrolyzed by water unless a large excess of the $\mathrm{CrO}_{4}$ ion is present. It gives off its water of crystallization below $200^{\circ}$ and if heated to about $300^{\circ}$ it melts with loss of weight. The melted mass is apparently a mixture of $\mathrm{K}_{2} \mathrm{Cr}_{2} \mathrm{O}_{i}$ and $\mathrm{Tl}_{2} \mathrm{Cr}_{2} \mathrm{O}_{i}$, since all the thallium is in the thallous condition and the loss of weight corresponds to the loss of two atoms of oxygen for every mulecule of $\mathrm{Tl}_{2} \mathrm{O}_{3}$.

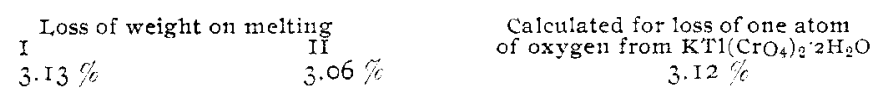

In conclusion I wish to thank Professor L. M. Dennis for many valuable suggestions.

CORNELL UNTVERSTY,

Jantlaty, 1907 .

\title{
ON FERROUS AND FERRIC SULPHIDES.
}

BY H. N. STOKES.

Received January II, 1907.

The appearance of a paper by Konschegg and Malfatti ${ }^{2}$ on the soluble sulphide of iron causes me to call attention to some uncompleted experiments made some time ago by myself in the laboratory of the U. S. Geological Survey. Being unable to continue the work, I state them ${ }^{1}$ Z. Anai. Chem1., 45, 747 (1906). 
with the hope that the method employed may be found of use to those interested in carrying the subject further.

It is invariably stated in recent text books that alkali sulphides precipitate from solutions of ferric salts a mixture of ferrous sulphide and sulphur and no mention is made of the possible formation of ferric sulphide. Berzelius' ${ }^{2}$ states that ferric sulphide is formed when a neutral solution of ferric sulphate is added drop by drop to a solution of an alkali sulphide, but this observation seems to have been generally overlooked. Phipson ${ }^{2}$ obtained ferric sulphide by treating a ferric chloride solution containing free chlorine or sodium hypochlorite with yellow ammonium sulphide.

If we suppose ferrous sulphide, which is black, to react with zinc hydroxide, which is white, according to the equation

$$
\mathrm{FeS}+\mathrm{Zn}(\mathrm{OH})_{2}=\mathrm{Fe}(\mathrm{OH})_{2}+\mathrm{ZnS}
$$

we shall get a product, which, if the reaction is complete, will be white. If, however, ferric sulphide, $\mathrm{Fe}_{2} \mathrm{~S}_{3}$, which is black, reacts with zinc hydroxide, after the equation

$$
\mathrm{Fe}_{2} \mathrm{~S}_{3}+3 \mathrm{Zn}(\mathrm{OH})_{2}=2 \mathrm{Fe}(\mathrm{OH})_{3}+3 \mathrm{ZnS}
$$

we shall obtain a product, which, if the reaction is complete, will be a mixture of white zinc sulphide with red ferric hydroxide. In these reactions, therefore, we may have a convenient method of diagnosing the nature of our iron sulphide precipitate. In the following experiments I employed zinc hydroxide in the convenient form of a solution of zinc chloride in ammonia. As air was carefully excluded and as zinc hydroxide is in no sense an oxidizer, the formation of ferric hydroxide from an iron sulphide may be taken as evidence that the sulphide is ferric, not ferrous sulphide.

A solution of 0.2 gram ferrous sulphate, which had been treated with hydrogen sulphide to reduce any ferric compound, was placed in a small flask, the iron completely precipitated as sulphide by a slight excess of colorless ammonium sulphide, and the flask then completely filled with ammoniacal zinc chloride and corked. The precipitate was unchanged in appearance after 24 hours standing, neither did it change on boiling. In a second experiment, conducted in an exhausted bomb tube, the ferrous sulphide was not acted on at $100^{\circ}$, but on heating an hour at $160^{\circ}-170^{\circ}$, it was converted into a greyish white precipitate, obviously zinc sulphide, containing perhaps some ferrous hydroxide, though this had in part dissolved in the ammoniacal solution. Amorphous ferrous sulphide is therefore not acted on in the cold by an ammoniacal solution of zinc hydroxide and only slowly on heating to $160^{\circ}-170^{\circ}$.

A ferric chloride solution was precipitated in the cold by ammonia; to

${ }^{1}$ Lehrbuch der Chemie, 2, 366 (I826).

${ }^{2}$ Chem. News, 30, I39 (1874). 
the emulsion of ferric hydroxide was added colorless ammonium sulphide until, after standing, the latter was permanently in excess; ammoniacal zinc chloride was added and the flask filled with air free water and corked. In two hours the stilphide had become completely converted into ferric hydroxide. In another similar experiment the conversion was complete in less time, while on boiling the transformation invariably completed itself instantly.

Io cc. Io per cent. ferric chloride was precipitated in the cold with potassium hydroxide and treated with a slight excess of freshly prepared normal potassium sulphide, with which it was allowed to stand for a time. The precipitate together with the deep green solution was then treated with an excess of a solution of zinc chloride in potassium hydroxide, which almost immediately, in the cold, converted it into a red mixture, ferric hydroxide with zinc sulphide. If the product of the action of the sulphide on the ferric hydroxide had been, or had contained a mixture of ferrous sulphide with sulphur, the latter would have been taken up by the alkali, forming a mixture of suiphide and thiosulphate, and after removing the sulphide by zinc hydroxide, the thiosulphate would remain in solution. As a matter of fact, the alkaline solution on acidifying and heating gave a barely visible turbidity from free sulphur, showing that thiosulphate was absent,${ }^{1}$ and that the sulphide must have consisted of ferric sulphide, not a mixture of ferrous sulphide and sulphur.

0.2 gram ferrous sulphate, freed from traces of ferric salt by hydrogen sulphide, was precipitated by a solution of ammonium polysulphide. The flask was then filled with ammoniacal zinc chloride solution and corked. Within a few hours the sulphide had become completely converted into ferric hydroxide. There was no iron in solution, showing the absence of ferrous hydroxide. A similar preparation, on boiling, was instantly converted into ferric hydroxide. Hence polysulphides precipitate ferrous salts as ferric sulphide.

A curious point in this connection is that a solution of sodium polysulphide, made by saturating sodium sulphide with sulphur, does not react with freshly precipitated ferric hydroxide, either hot or cold, neither does it, if concentrated, precipitate a strong solution of zinc chloride in potas. sium hydroxide in the cold, but only on diluting or heating. It, however, precipitates ferrous, lead and cadmium salts.

Ferric hydroxide was converted into ferric sulphide by adding ammonium sulphide in such amount as not to leave an excess of the latter, and was then boiled in a flask in a current of carbon dioxide. In less than half an hour the hydrogen sulphide was completely expelled and the precipitate had regained its original color. Amorphous ferric sulphide then

1 The formation of thiosulphate by the action of alkaline solutions on pyrite and other sulphides, will be treated of in the following paper. 
shows in a marked degree the property of hydrolysis common to ferric salts.

\section{Summary.}

The main conclusions from the above experiments may be thus summarized.

I. Precipitated ferrous sulphide does not react with zinc hydroxide in the cold, or at boiling temperature, and only slowly at $I 60^{\circ}$, the products being colorless ferrous hydroxide and zinc sulphide.

2. In general, the statement that ferric salts give a mixture of ferrous sulphide and sulphur, when precipitated in alkaline solution by an alkaline sulphide is erroneous; the product is ferric sulphide, which reacts with zinc hydroxide, rapidly in the cold, instantly on boiling, to form ferric hydroxide and zinc sulphide.

3. Alkaline polysulphides precipitate ferrous salts as ferric sulphide.

4. Ferric sulphide readily hydrolyzes into ferric hydroxide and hydrogen sulphide at $100^{\circ}$.

BUREAU OF STANDARDS,

WASHINGTON, D. C.

\section{EXPERIMENTS ON THE ACTION OF VARIOUS SOLUTIONS ON PYRITE AND MARCASITE}

BY H. N. STOKES.

Received January II, 1907.

The experiments described in this paper from part of an unfinished investigation undertaken by the writer before his transfer from the U. S. Geological Survey to the Bureau of Standards. While the work is by no means complete, the results would appear to have some geological significance and are published now in the hope that they may contribute somewhat to an understanding of the formation and decomposition of sulphides. As the writer will be unable to pursue the subject further, he hopes that the work may be continued and enlarged by other chemists working along geological lines.

Without attempting to discuss the geological bearings, the results may be briefly summarized as follows: Pyrite and marcasite are decomposed by circulating alkaline waters which leave hematite or hydrated ferric oxide and carry away the sulphur in the form of alkali sulphides and thiosulphate. The sulphides may react in another place with metallic salts giving sulphides; the thiosulphates may either remain unchanged or may react with copper or silver compounds, giving sulphides of these metals and alkali sulphates. This conversion of pyrite into hematite occurs in the absence of free oxygen; the occurrence of ferric oxides as transformation products of pyrite is therefore not in itself a proof of the action of aerated water or other oxidizing agents. 